Contract No. and Disclaimer:

This manuscript has been authored by Savannah River Nuclear Solutions, LLC under Contract No. DE-AC09-08SR22470 with the U.S. Department of Energy. The United States Government retains and the publisher, by accepting this article for publication, acknowledges that the United States Government retains a non-exclusive, paid-up, irrevocable, worldwide license to publish or reproduce the published form of this work, or allow others to do so, for United States Government purposes. 


\section{POTENTIAL FOR STRESS CORROSION CRACKING OF A537 CARBON STEEL NUCLEAR WASTE TANKS CONTAINING HIGHLY CAUSTIC SOLUTIONS}

\author{
Poh-Sang Lam
}

\author{
Craig S. Stripling \\ Materials Science and Technology \\ Savannah River National Laboratory (SRNL) \\ Aiken, South Carolina 29808, USA
}

\author{
James B. Elder III
}

\section{ABSTRACT}

The evaporator recycle streams of nuclear waste tanks may contain waste in a chemistry and temperature regime that exceeds the current corrosion control program, which imposes temperature limits to mitigate caustic stress corrosion cracking (CSCC). A review of the recent service history found that two of these A537 carbon steel tanks were operated in highly concentrated hydroxide solution at high temperature. Visual inspections, experimental testing, and a review of the tank service history have shown that CSCC has occurred in uncooled/un-stress relieved tanks of similar construction. Therefore, it appears that the efficacy of stress relief of welding residual stress is the primary corrosion-limiting mechanism. The objective of this experimental program is to test A537 carbon steel small scale welded U-bend specimens and large welded plates $(30.48 \times 30.38 \times 2.54 \mathrm{~cm})$ in a caustic solution with upper bound chemistry (12 M hydroxide and $1 \mathrm{M}$ each of nitrate, nitrite, and aluminate) and temperature $\left(125^{\circ} \mathrm{C}\right)$. These conditions simulate worst-case situations in these nuclear waste tanks. Both as-welded and stress-relieved specimens have been tested. No evidence of stress corrosion cracking was found in the U-bend specimens after 21 days of testing. The large plate test was completed after 12 weeks of immersion in a similar solution at $125{ }^{\circ} \mathrm{C}$ except that the aluminate concentration was reduced to $0.3 \mathrm{M}$. Visual inspection of the plate revealed that stress corrosion cracking had not initiated from the machined crack tips in the weld or in the heat affected zone. NDE ultrasonic testing also confirmed subsurface cracking did not occur. Based on these results, it can be concluded that the environmental condition of these tests was unable to develop stress corrosion cracking within the test periods for the small welded U-bends and for the large plates, which were welded with an identical procedure as used in the construction of the actual nuclear waste tanks in the 1960s. The absence of evidence of stress corrosion cracking and general corrosion in the laboratory-scaled specimens indicate that this type of nuclear waste tank is not susceptible to highly caustic solutions up to $12 \mathrm{M}$ hydroxide at $125^{\circ} \mathrm{C}$ when sufficient nitrite inhibitor is present.

\section{INTRODUCTION AND BACKGROUND}

The service history from 1998 to 2008 of two U. S. Department of Energy Savannah River Site (SRS) nuclear waste tanks showed that the nitrate concentration $\left[\mathrm{NO}_{3}^{-}\right]$ decreased to less than $1 \mathrm{M}$ while the hydroxide concentration $\left[\mathrm{OH}^{-}\right]$remained as high as $12 \mathrm{M}$. The temperatures in these tanks were also approaching 80 to $100{ }^{\circ} \mathrm{C}$. This condition exceeded the current waste tank corrosion control program, which imposes a temperature limit of $\left(60{ }^{\circ} \mathrm{C}\right)$ to mitigate caustic stress corrosion cracking (CSCC). It was concluded by an electrochemical experiment with solutions consisting of 10 $\mathrm{M}\left[\mathrm{OH}^{-}\right]$and up to $2 \mathrm{M}\left[\mathrm{NO}_{3}^{-}\right]$and at temperatures from 60 to $95^{\circ} \mathrm{C}$, that low-carbon steels may be susceptible to CSCC. That set of experimental data suggested that, at a reduced $\left[\mathrm{NO}_{3}^{-}\right]$level, the resulting corrosion potential $\left(\mathrm{E}_{\text {corr }}\right)$ was unable to suppress the initial active-passive transition peak, the

\footnotetext{
$\dagger$ This manuscript has been authored by Savannah River Nuclear Solutions, LLC under Contract No. DE-AC09-08SR22470 with the U.S. Department of Energy. The United States Government retains, and by accepting the article for publication, the publisher acknowledges that the Unites States Government retains, a non-exclusive, paid up, irrevocable worldwide license to publish or reproduce the published form of this work, or allow others to do so, for United States Government purposes.
} 
presence of which has been associated with stress corrosion cracking. Therefore, it led to a conclusion that these two tanks might rely solely on the relief of welding residual stress to provide protection against CSCC by diminishing the internal driving force to cause cracking in the heat affected zone (HAZ). The heat treatment for stress relief also resulted in the formation of an oxide film which would further delay the stress corrosion cracking (SCC) in the waste tanks.

In an earlier study [1], the nitrate stress corrosion cracking in A285 carbon steel nuclear waste tanks was shown to be effectively eliminated by relieving the welding residual stress through heat treatment. Figure 1, magnetic particle testing (MT) results, shows the stress corrosion cracks growing from the initial, machined seed cracks in an as-welded, non-heat treated A285 plate, which was submerged in a $5 \mathrm{M}$ sodium nitrate solution at $90{ }^{\circ} \mathrm{C}$. Meanwhile, no cracking could be found even by ultrasonic testing (UT) in the companion test plate which had been heat treated. The stress corrosion cracking was initiated from the seed cracks as early as two weeks following immersion in the aggressive solution (no inhibitors were present).

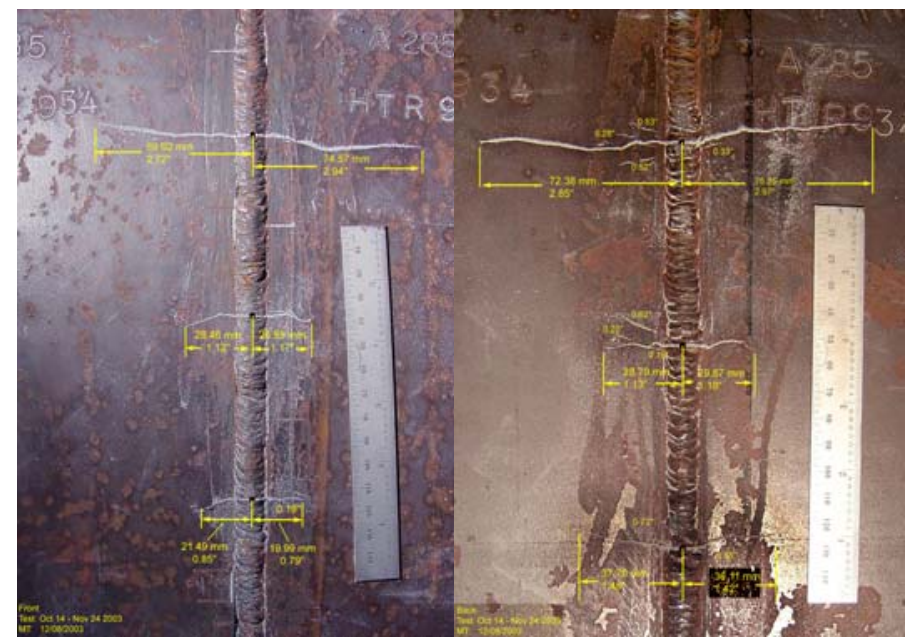

Front Side

Back Side

\section{Fig. 1 Nitrate stress corrosion cracking of the as-welded A285 plate [1].}

Following a similar approach for CSCC, a representative material of construction for these waste tanks, A537 carbon steel, was used to fabricate the test specimens (small scale welded U-bends and the large welded plates). These were tested in a highly caustic solution defined by the bounding chemistry conditions based on the service history (i.e., $12 \mathrm{M}$ hydroxide and $1 \mathrm{M}$ each of nitrate, nitrite, and aluminate) and a temperature of $125{ }^{\circ} \mathrm{C}$. The objective of the current investigation is two-fold: 1) to determine if CSCC can indeed occur under the test environment; and 2) if CSCC takes place in the as-welded specimens, it is necessary to confirm the efficacy of residual stress relief so the current state of these two tanks are temporarily protected from CSCC.

No cracking was found in the U-bend specimens within the scheduled 21-day test. Some U-bend specimens were left in the test station for up to 95 days and yet no stress corrosion cracking was observed. It should be noted that during the extended test, the concentrations of the test solution was changed to unknown states (more concentrated) and became sludge-like resulting from evaporation. Condensers were installed, but were not intended for very long testing beyond 21 days. The temperature was maintained at or slightly above $125^{\circ} \mathrm{C}$.

The large plate test has been concluded after 12 weeks of immersion in a $125^{\circ} \mathrm{C}$ caustic solution composed of $12 \mathrm{M}$ hydroxide, $1 \mathrm{M}$ nitrate, $1 \mathrm{M}$ nitrite, and $0.3 \mathrm{M}$ aluminate (slightly modified from the U-bend test solution which contained $1 \mathrm{M}$ aluminate). No surface stress corrosion cracking, as shown in Figure 1, was found by visual inspection. Ultrasonic testing was also conducted for the as-welded and the heat-treated plates. No stress corrosion cracking inside the plates was detected.

These test results lead to the conclusion that the chemistry environment for the testing at $125{ }^{\circ} \mathrm{C}$ provided a favorable condition for A537 to inhibit stress corrosion cracking. The cracking might have been retarded by the nitrite ions, which are strong oxidizing agents, and may have allowed the continuous formation of a protective oxide film on the test specimen surfaces. This has been demonstrated through the freshly exposed areas where Clarke's solution [2] was used immediately before immersion to remove the oxide formed at the machined crack tips at which stress corrosion cracking is most likely to occur.

Careful examination of the specimen conditions found that many distinct surface features originally on the mill sheet remained visible on the specimens after testing, and the detailed appearance of the weld beads was essentially unchanged. The specimen thinning was immeasurable with a micrometer. Therefore, the general corrosion is negligible for A537 carbon steel which has been exposed to $12 \mathrm{M}$ caustic solution for extended period of time.

It has been shown through the laboratory testing that stress corrosion cracking did not occur in the small welded U-bend specimens and in the large plates fabricated with an identical welding procedure as was used in the construction of these two SRS waste tanks in the 1960s. The observations of no evidence of stress corrosion cracking or general corrosion in the laboratory specimens indicate that this type of nuclear waste tanks are not susceptible to highly caustic solutions up to $12 \mathrm{M}$ hydroxide at $125^{\circ} \mathrm{C}$ when sufficient nitrite inhibitor is present.

\section{EXPERIMENTS}

Two types of specimens were used: 1) small scale U-bend (Fig. 2) made from a strip of $12.7 \mathrm{~cm}$ (5 in.) long, $2.54 \mathrm{~cm}$ (1 in.) wide, and $3.18 \mathrm{~mm}(1 / 8 \mathrm{in}$.) thick; and 2) large plate of dimensions $30.48 \times 30.48 \times 2.54 \mathrm{~cm}(12 \times 12 \times 1$ in. $)$ with machined 
seed cracks (Fig. 3). Each specimen contained a weld. Heat treatment to relieve the welding residual stress was applied to half of the specimen population. Both sets of specimens (aswelded and heat-treated) were submerged side by side in the same caustic solution at $125^{\circ} \mathrm{C}$.

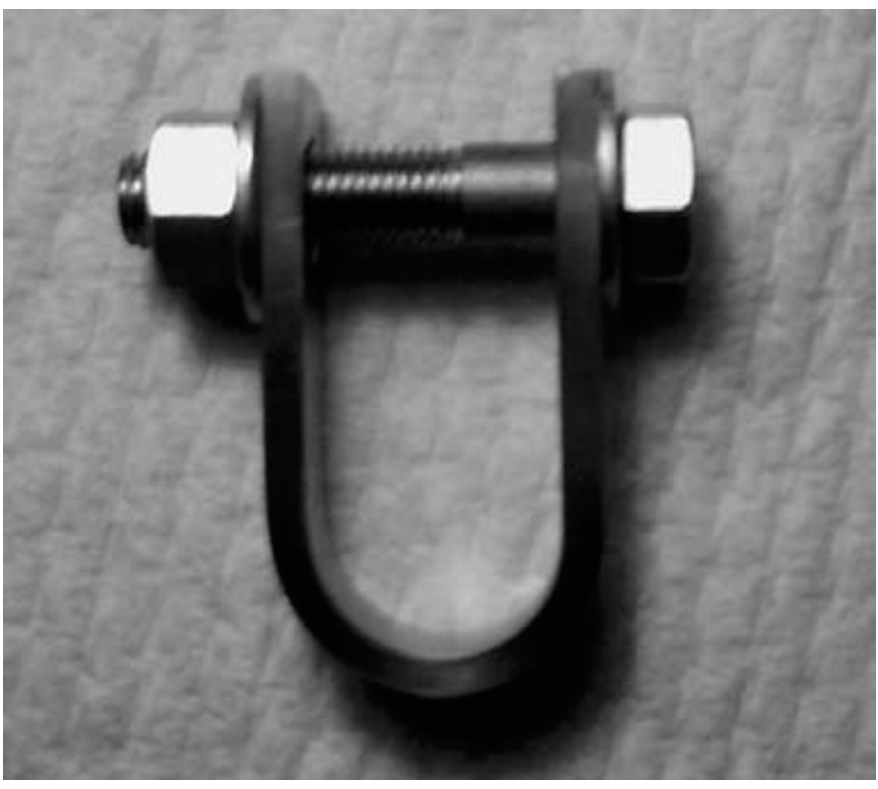

Fig. 2 U-bend specimen made from a $12.7 \times 2.54 \times 3.18 \mathrm{~mm}$ strip.

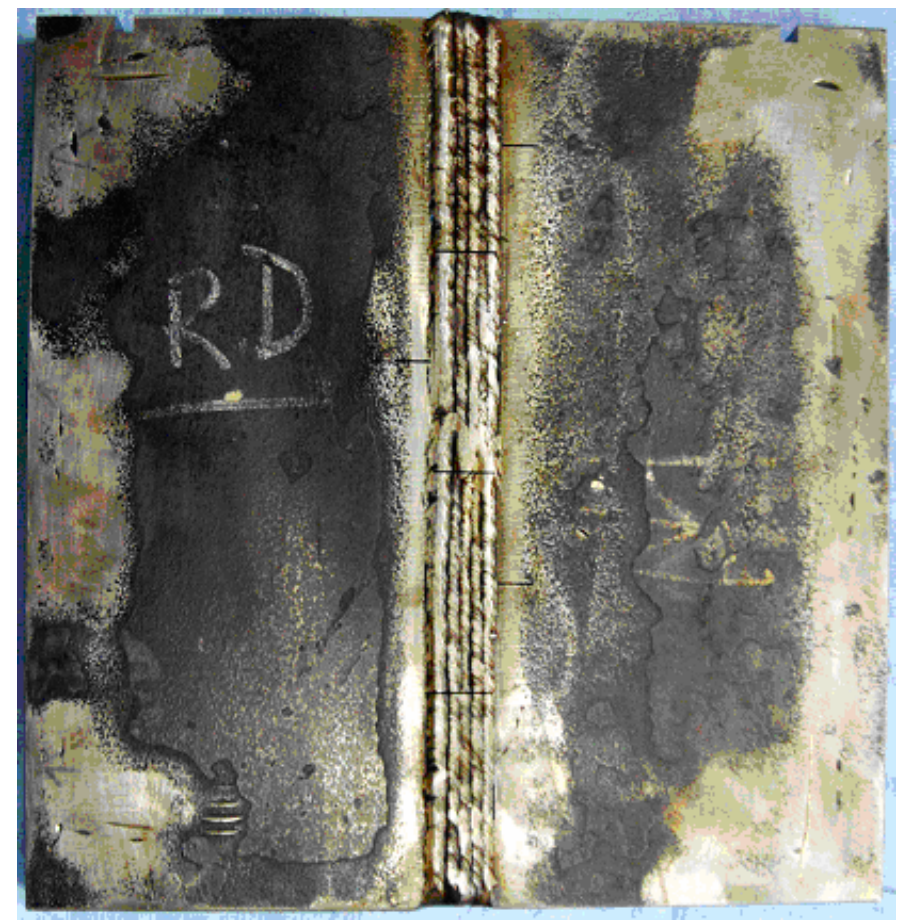

Fig. 3 Large-plate specimen $(30.48 \times 30.48 \times 2.54 \mathrm{~cm})$.

\section{Test Solutions}

The test condition was chosen to bound the chemistry and temperature histories since 2002 for the two waste tanks. The test solution was made from $12 \mathrm{M}$ hydroxide $\left[\mathrm{OH}^{-}\right], 1 \mathrm{M}$ nitrate $\left[\mathrm{NO}_{3}^{-}\right], 1 \mathrm{M}$ nitrite $\left[\mathrm{NO}_{2}^{-}\right]$, and $1 \mathrm{M}$ (for the U-bend test) or $0.3 \mathrm{M}$ (for the large plate test) aluminate $\left[\mathrm{AlO}_{2}^{-}\right]$by dissolving salts of $\mathrm{NaOH}, \quad \mathrm{NaNO}_{3}, \mathrm{NaNO}_{2}, \quad$ and $2\left(\mathrm{NaAlO}_{2}\right) \cdot 3 \mathrm{H}_{2} \mathrm{O}$ at above-room temperature. After the solution was transferred to the immersion test vessels, the temperature was raised to the target $125^{\circ} \mathrm{C}$ in three 1.6-liter polytetrafluoroethylene (PTFE) beakers for the U-bend test and a 6-gallon alloy C-276 (UNS N10276) test tank for the large plate test.

An adequate ratio of solution volume to specimen surface area was maintained. The ASTM G 123-00 (Reapproved 2005) [3], "Standard Test Method for Evaluating Stress Corrosion Cracking of Stainless Alloys with Different Nickel Content in Boiling Acidified Sodium Chloride Solution," suggests that the ratio be $5 \mathrm{ml} / \mathrm{cm}^{2}$ or $33 \mathrm{ml} / \mathrm{in}^{2}$ (G 123 Paragraph 10.6). The corrosion product build-up due to general corrosion during this CSCC experiment was not expected to affect the test environment (solution) as much as that under the conditions specified in ASTM G 123. Therefore, using the ratio recommended in ASTM G 123 was considered appropriate.

\section{Test Material Selection}

The SRS waste tanks being investigated are of a type constructed with carbon steels ASTM A516-70 or A537. These two carbon steels have similar carbon contents and yield strength ranges. They have been shown to exhibit comparable SCC resistance. The welded A537 was chosen as the test material for investigating CSCC behavior. The nominal composition of A537 carbon steel is listed in Table 1. The carbon content of A537 used in the actual waste tanks ranged from 0.14 to 0.23 wt. $\%$.

Table 1 Nominal Composition of A537 Class I Carbon Steel (wt.\%)

\begin{tabular}{|c|c|c|c|c|c|c|c|c|}
\hline $\mathrm{C}$ & $\mathrm{Cr}$ & $\mathrm{Cu}$ & $\mathrm{Mn}$ & $\mathrm{Mo}$ & $\mathrm{Ni}$ & $\mathrm{P}$ & $\mathrm{S}$ & $\mathrm{Si}$ \\
\hline 0.24 & 0.25 & 0.35 & $0.65-$ & 0.08 & 0.25 & 0.035 & 0.04 & $0.13-$ \\
$(\max )$. & $(\max )$. & $(\max )$. & 1.4 & $(\max )$. & $(\max )$ & $(\max )$. & $(\max )$. & 0.55 \\
\hline
\end{tabular}

\section{U-bend Test}

The U-bend specimens were first cut from A537 mill sheet, ground from the original $9.525 \mathrm{~mm}(3 / 8 \mathrm{in}$.) to the desired $3.18 \mathrm{~mm}$ ( $1 / 8$ in.), then welded perpendicular to the rolling direction. Shielded metal arc welding (SMAW) was applied with single pass on each side of the specimen. This welded plate was then machined into a strip with dimensions of 12.7 $\mathrm{cm}$ (5 in.) long, $2.54 \mathrm{~cm}$ (1 in.) wide, and $3.18 \mathrm{~mm}(1 / 8$ in.) thick with the weld in the center of the strip in the longitudinal direction. The strip was bent around a mandrel with a radius of 
$12.8 \mathrm{~mm}(0.505 \mathrm{in}$.) to form a U-bend specimen. The specimen fabrication and assembly are consistent with ASTM G 30 - 97 [4] (Reapproved 2003) entitled "Standard Practice for Making and Using U-Bend Stress-Corrosion Test Specimens."

Prior to submerging in the test solution, each pair of the specimen legs was bent approximately parallel. To maintain the shape without relaxing the elastic tensile strain, the legs were tightened by nuts and a screw which are properly insulated with PTFE washers and sleeve to avoid the galvanic effects between two different materials (Fig. 2).

\section{Stress Relief Heat Treatment for U-bend Specimens}

Two sets of U-bend specimens were tested simultaneously: (1) as-welded and (2) heat-treated for welding residual stress relief. The heat treatment was guided by 1968 ASME Boiler and Pressure Vessel Code Section VIII, Paragraph UCS-56, which was used in the construction of SRS nuclear waste storage tanks in the 1960s. The heat treatment procedure is summarized as follows:

(1) The heat treatment is conducted in air.

(2) Heating from ambient to $593{ }^{\circ} \mathrm{C}\left(1100{ }^{\circ} \mathrm{F}\right)$ at a rate of $50^{\circ} \mathrm{C} /$ hour $\left(90^{\circ} \mathrm{F} /\right.$ hour $)$.

(3) Holding at $593{ }^{\circ} \mathrm{C}\left(1100{ }^{\circ} \mathrm{F}\right)$ for 60 minutes.

(4) Cooling to ambient at a rate of $64^{\circ} \mathrm{C} /$ hour $\left(115^{\circ} \mathrm{F} /\right.$ hour $)$.

\section{U-bend Test Setup and Procedure}

The testing used a total of eight U-bend specimens, four of which were as-welded (fabricated and assembled per ASTM G 30 [4]) and the other four were heat treated prior to assembling. These eight specimens were submerged in three commercially available PTFE beakers filled with the pre-mixed caustic solution.

The overall laboratory setup can be seen in Figure 4 . The duration of the testing was 21 days. The U-bend specimens were examined periodically for cracking during the test period.

\section{Large Plate Test}

The large plate test was designed to simulate the corrosion response of welded waste tanks with highly caustic waste form at very high temperature. The size of the plate specimen allows the use of the actual waste tank wall thickness and the actual welding practice as specified in the original engineering drawings. The welding of the large plate also provides a constraint which is inherent to a large structure when welding is performed during construction. This constraint may affect the severity of welding residual stress that is developed in the heat affected zone. Similar to the U-bend test, an as-welded and a stress-relieved specimen were used. Identical heat treatment was used to relieve welding residual stress, as in the case of U-bends. However, in the large plates, seed cracks (both through-the-plate and part-through cracks) were introduced across the weld and in the HAZ to create favorable SCC initiation sites [1]. The composition of the test solution was adjusted for the large plate test, that is, the aluminate concentration was changed to $0.3 \mathrm{M}$ from the $1 \mathrm{M}$ solution used in the U-bend test.

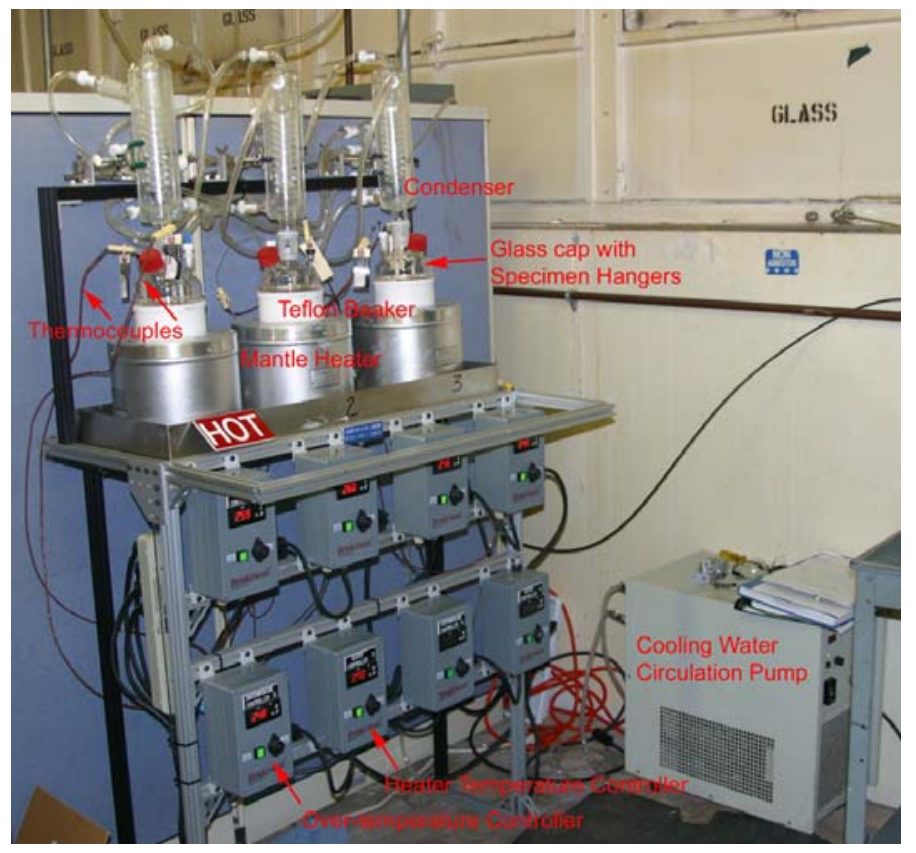

Fig. 4 U-bend test station.

The test period for the large plate test was 12 weeks. The stress corrosion cracking, if any, could be observed visually by periodic inspection during the test. The magnetic particle test (MT) would be an option at the end of test to reveal the details of surface cracking. Non-destructive UT would be used to detect the presence of internal cracking. A baseline UT was performed prior to the beginning of testing to aide in evaluation of any cracking detected at the conclusion of test. By comparing the pre- and post-test UT data, any cracking, either internal or exposed to the surface, could be detected and sized more accurately; and its initiation site, and the cause of subsequent orientation and arrest, could be identified.

\section{Large Plate Specimen Fabrication and Welding Procedure}

The plate specimens were fabricated in a manner similar to those used in the previous nitrate SCC testing (welded A285 carbon steel plates in $5 \mathrm{M}$ sodium nitrate solution at $90{ }^{\circ} \mathrm{C}$ [1]). To be consistent with the U-bend specimens, the weld orientation was chosen to be perpendicular to the rolling direction of the steel mill sheet. Therefore, two $15.24 \times 30.48$ $\mathrm{cm}(6 \times 12$ in.) plates were cut from an $2.54 \mathrm{~cm}$ (one inch) thick A537 sheet and then butt-welded to form a $30.48 \times 30.46 \times 2.54$ $\mathrm{cm}(12 \times 12 \times 1$ in. $)$ specimen plate. Such an arrangement ensures that the weld is in the desired orientation. 
The thickness of the large plate specimen is $2.54 \mathrm{~cm}$ (one inch), which was chosen based on the thickness of the plate at the location where the highest service temperature was found in one of the two tanks, near the bottom knuckle. Within that bottom plate, the most susceptible area for CSCC to occur is the vertical seam, this weld is marked in red in Figure 5 (part of the original blue print file). The original welding document from Nooter Corporation (1964) specified that the SMAW was used in butt-joining the tank wall with a double K-notch. The Oxweld 65 (brand name for ER70S-2 wire) was used for the initial weld between the closest point along the double-K notch; and the filler metal, coated E-7018, was used to complete the weld on one side of the tank wall (as many passes as necessary). This process was repeated for the other side of the tank wall. The same welding procedure and parameters were adopted to fabricate the plate specimens for the CSCC experiment. However, there were slight differences in the actual welding of the two plates, for example, the length of each pass and the number of passes.

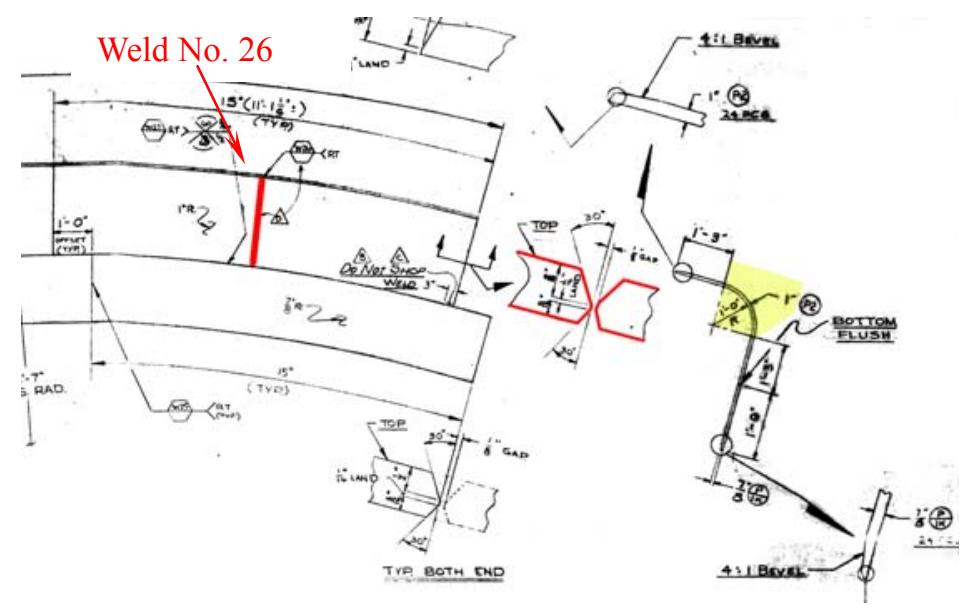

Fig. 5 Vertical seam weld No. 26 in the bottom knuckle area (thickness: $2.54 \mathrm{~cm}$ or 1 inch).

\section{Stress Relief Heat Treatment for the Large Plate} Specimen

The same heat treatment was applied to the large plate specimen as described earlier for the U-bend specimens. This information is repeated below:

(1) The heat treatment is conducted in air.

(2) Heating from ambient to $593{ }^{\circ} \mathrm{C}\left(1100{ }^{\circ} \mathrm{F}\right)$ at a rate of $50{ }^{\circ} \mathrm{C} /$ hour $\left(90^{\circ} \mathrm{F} /\right.$ hour $)$.

(3) Holding at $593{ }^{\circ} \mathrm{C}\left(1100{ }^{\circ} \mathrm{F}\right)$ for 60 minutes.

(4) Cooling to ambient at a rate of $64^{\circ} \mathrm{C} /$ hour $\left(115^{\circ} \mathrm{F} /\right.$ hour $)$.

\section{Seed Cracks}

Unlike the U-bend specimens, seed cracks were machined into the large plate specimens and serve as the initiation sites for stress corrosion cracking. Note that for the stress-relieved plate specimen, the heat treatment must be performed prior to machining the seed cracks.

The schematic seed crack placement and crack types can be seen in Figure 6. The actual seed cracks are shown in the insets of the figure. The electric discharge machining (EDM) was used to fabricate these cracks so the crack tips can be as sharp as possible. Due to the EDM wire or electrode size, the crack tip maintains a small but finite radius (e.g., $0.38 \mathrm{~mm}$ or 0.015 in.).

The three types of machined cracks are (see Figure 6):

1) V1, V2, and V3: vertical cracks through the thickness of the plate and across the weld (Fig. 7);

2) V4, V5, and V6: vertical cracks partly through plate in the heat affected zone perpendicular to the weld (Fig. $8)$; and

3) P1, P2, and P3: cracks parallel to the weld and partly through plate in the HAZ along the edge of the weld (Fig. 9).

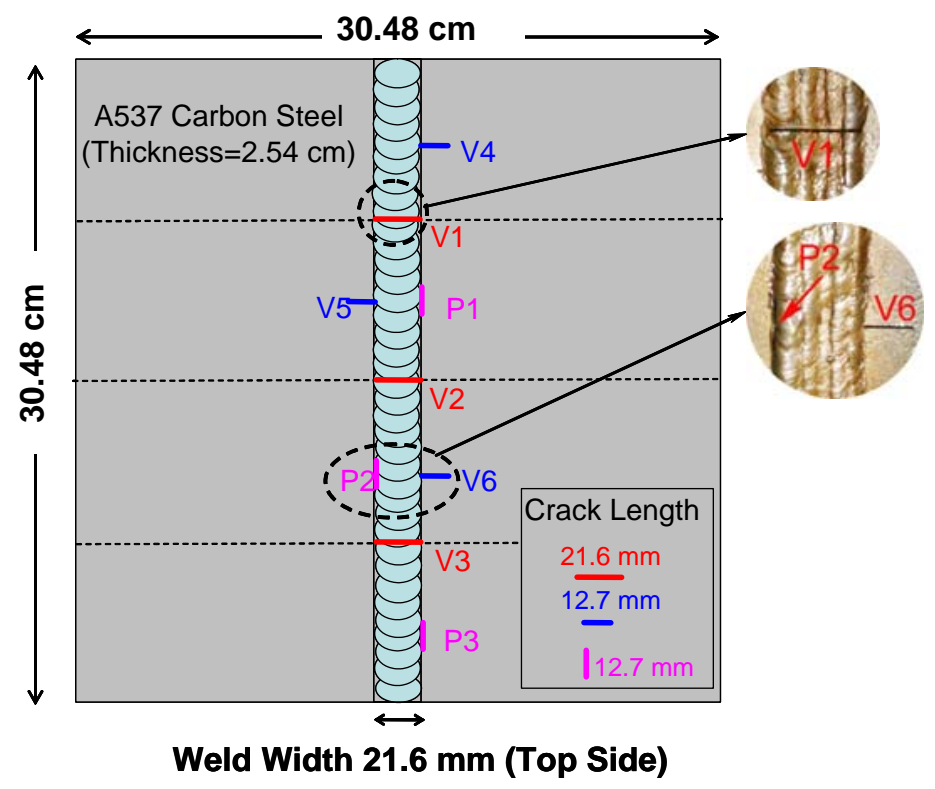

Fig. 6 Welded large plate specimen with machined cracks.

\section{Large Plate Test Tank and Experimental Station}

Typical stainless steels, especially their weldment, may corrode significantly during long exposure to highly caustic solutions at temperature as high as $125^{\circ} \mathrm{C}$ (or slightly above, because the temperature control is of oscillatory nature). As a result, the nickel-molybdenum-chromium alloy, alloy C-276, was selected for constructing the immersion tank. This material, along with its welds, is known to be corrosionresistant in highly caustic solutions at high temperatures. The design of the immersion tank was based on the specimen 
dimension $30.48 \times 30.48 \times 2.54 \mathrm{~cm}(12 \times 12 \times 1$ in. $)$ and the ratio of solution volume to specimen surface area (i.e., $5 \mathrm{ml} / \mathrm{cm}^{2}$ or $33 \mathrm{ml} / \mathrm{in}^{2}$, suggested by ASTM G 123 [3]). The tank is $45.72 \mathrm{~cm}$ (18-in.) high with a cross-section of $45.72 \times 16.51 \mathrm{~cm}$ (18×6.5 in.) with a total volume of 34.5 liters ( 9.1 gallons) which could accommodate 6 gallons of the test solution required by ASTM G 123 [3]. The thickness of the tank wall is $9.525 \mathrm{~mm}(3 / 8 \mathrm{in}$.). The test tank was designed in such a manner that none of the C-276 plate edges (i.e., end-grains) would be exposed to the solution, which makes the test tank even more corrosion-resistant. The test solution is not filled to the top of the tank. A $6.35 \mathrm{~cm}\left(2^{1 / 1} / 2 \mathrm{in}\right.$.) headspace is left when the test plates and hangers (racks) (Figure 10) are in position with a liquid volume of 25 liters (6.6 gallons).

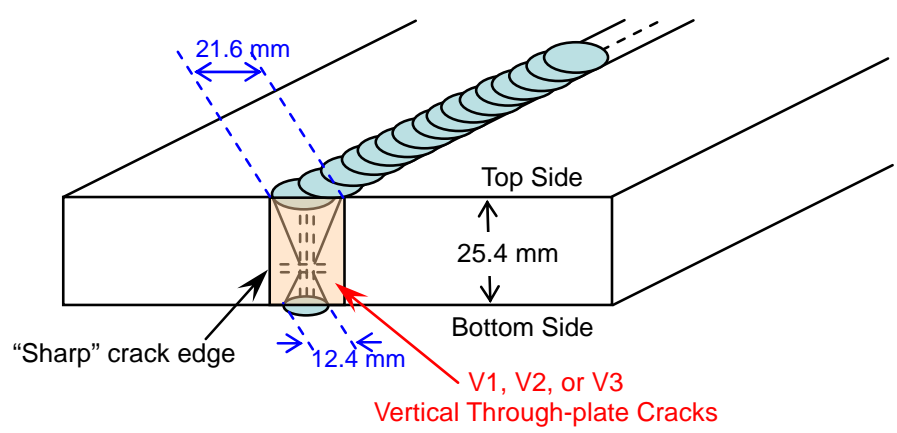

Fig. 7 Through-the-plate cracks across the weld (V1, V2, and V3).

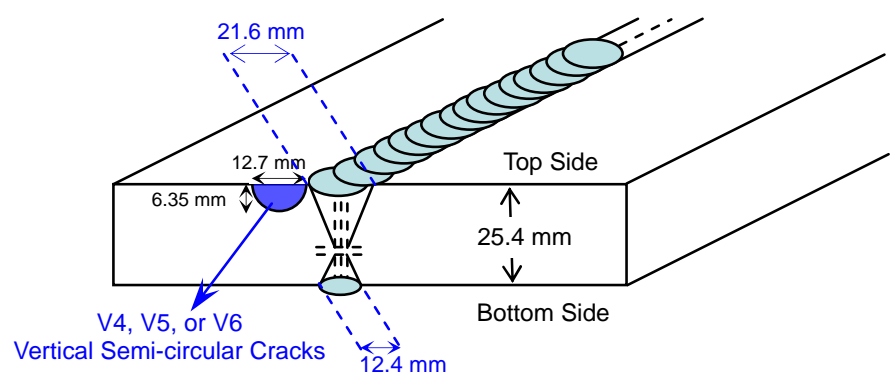

Fig. 8 Semi-circular surface cracks perpendicular to the weld (V4, V5, and V6).

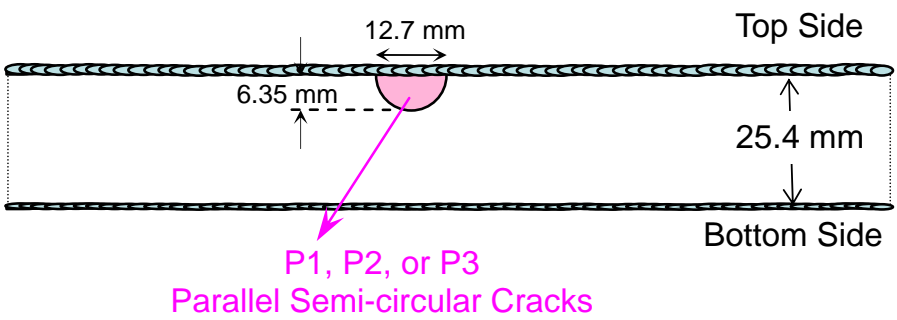

Fig. 9 Semi-circular surface cracks parallel to the weld (P1, P2, and P3).
A heating unit with controller was designed to maintain the test temperature at $125{ }^{\circ} \mathrm{C}$ for an extended period of time. The heaters are housed in flexible silicone which adheres to the sides of the test tank. They are rated to function up to $232^{\circ} \mathrm{C}$ $\left(450{ }^{\circ} \mathrm{F}\right)$ but the adhesive is only rated at $149^{\circ} \mathrm{C}\left(300^{\circ} \mathrm{F}\right)$. Two (2) adhesive-backed thermocouples have been placed on the tank surface at the heater location to make sure the adhesive does not exceed this temperature during the startup process. When the temperature reaches the setpoint and stabilizes, thermocouple plugs may be disconnected from the heater thermocouples and connected to the thermocouples monitoring the liquid. This arrangement verifies liquid temperature after keeping the heater's adhesive within its desired temperature range.

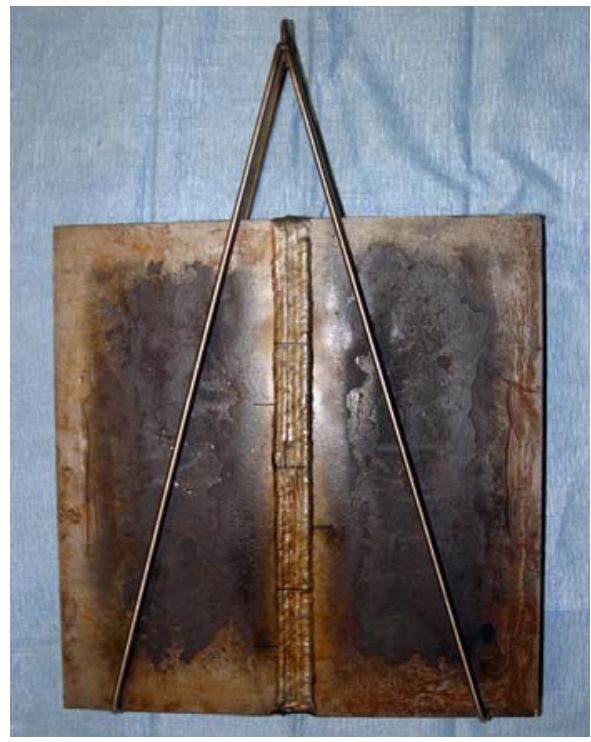

\section{Fig. 10 Positioning of the test plate on the rack (hanger).}

The heaters operate simultaneously and are controlled by a simple temperature controller backed up by a programmable digital over-temperature controller. Each has an independent thermocouple input. A high temperature, corrosion resistant level sensor (float) will cut off the power supply to the heaters if the liquid level drops below $35.56 \mathrm{~cm}$ (14 in.) measured from the bottom

The controller (the assembly of all the electronic equipment) and heaters are protected by a ground fault circuit interrupter (GFCI) which switches power off within 5 milliseconds of any current fault. A fast-blow fuse protects the solid state relay and all heater power wiring.

Because the weight of each large plate specimen is about $18 \mathrm{~kg}(40 \mathrm{lbs})$ and the specimens are lifted periodically above the heated caustic solution for visual inspection for cracking, a small manual rigging device is included in the design for safe operation during the test. Each carbon steel plate is suspended in a cradle (i.e., hanger or rack, see Fig. 10). The rack is made 
of stainless steel. Therefore, it is insulated from the A537 carbon steel plate by wrapping PTFE tapes throughout the rack/holder. Furthermore, two notches were machined on the bottom edge of each test plate so the rack will catch the test plate securely. Because of the presence of the notches, the holder may get caught inside the notches and therefore is unable to provide an insulated barrier between the bottom edge of the test plate (A537) and the bottom of the test tank (alloy C276). A PTFE plate was placed on the bottom of the tank to avoid direct contact between A537 and C-276.

The test plate and the rack (holder) were designed to be lifted with a winch from or lowered into the solution in the test tank which has been filled with highly caustic solution and at high temperature. The winch is equipped with a brake and clutch and must be manually powered up and down. The test tank is supplied with a lid which may be replaced once one plate is brought above the top of the test tank. This eliminates the possibility of corrosive material splashing out if objects are accidentally dropped into the test solution.

Secondary containment is required for any testing involving aggressive solutions. Secondary containment for these tests was constructed of stainless steel with a volume of 44.3 liters (11.7 gallons), which is sufficient to contain all the liquid should the test solution release from the test tank. The rapidly dropping temperature of the released liquid as it becomes exposed to ambient conditions allows the use of stainless steel for this application (i.e., using the costly material of the test tank, Hastelloy C-276, is not necessary for temporary containment/storage of the low temperature caustic solution).

All the components of the large plate experimental station and the laboratory layout are shown in Figure 11.

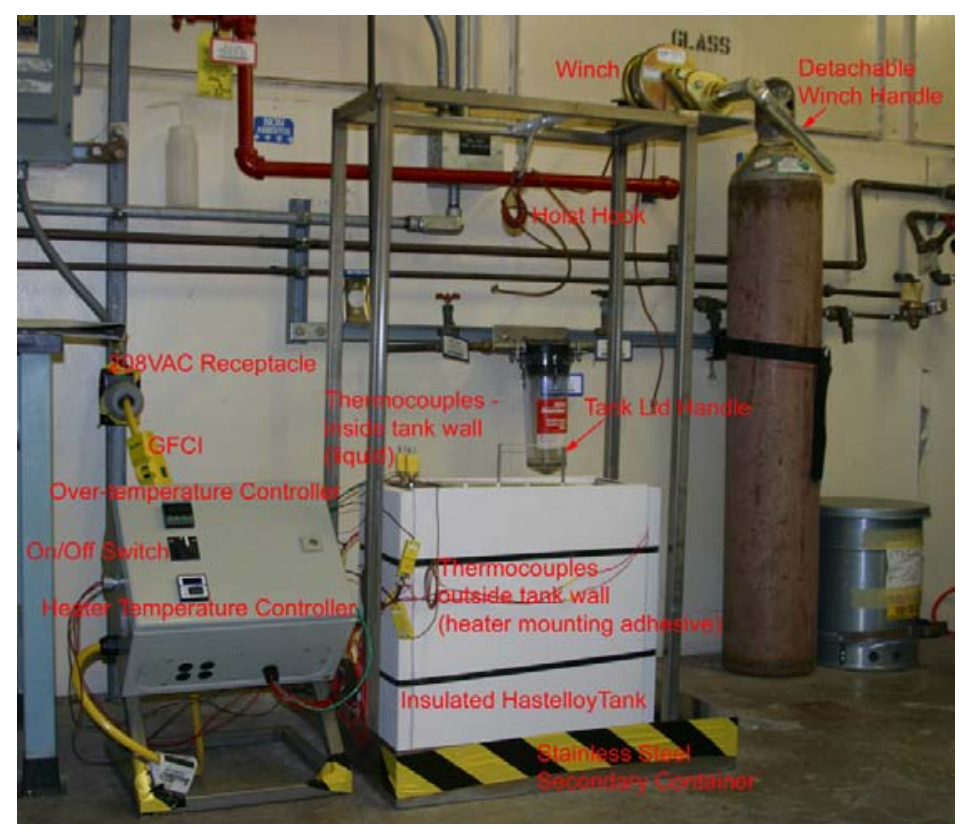

Fig. 11Large plate experimental station.

\section{Large Plate Test Procedure}

Pre-test UT had been performed to characterize the initial sizes of the machined cracks. After the test was complete, a second UT scan was performed and data were compared with the baseline so any interior cracking can be detected.

Prior to submerging the large plate specimens into the caustic solution, the machined cracks were cleaned with Clarke's solution [2] to remove the corrosion products (oxide) on the crack surfaces that would have formed naturally in the atmosphere. This treatment ensured that the caustic test solution will directly attack the fresh metal surface of the cracks, and the obstructing oxides will not interfere, especially at the crack tip where the welding residual stress is operating and tends to open the crack.

The Clarke's solution can be prepared by dissolving 20 grams of $\mathrm{Sb}_{2} \mathrm{O}_{3}$ and 50 grams of $\mathrm{SnCl}_{2}$ in $1000 \mathrm{ml}$ of concentrated $\mathrm{HCl}$ (see Reference [2], ASTM G 1 - 03 "Standard Practice for Preparing, Cleaning, and Evaluating Corrosion Test Specimens," Annex A1, Designation C.3.1 for iron and steel). A small amount of Clarke's solution was applied to the cracks on the specimen plate surface with an eyedropper. The treated area was rinsed with distilled water and then with ethanol to remove the residual chlorides trapped in the cracks. Like the test tank which contains highly caustic solution, this treatment of applying the Clarke's solution also required a secondary container to catch the spills.

After the plate specimen was submerged in the test solution, periodic inspections were performed by lifting the plate above the test solution with the winch and hoist hook (Fig. 12). The total exposure time of the large plate specimen was set to 12 weeks. No evaporation control was attempted (e.g., such as the condensers in the U-bend test). However, a small amount of insulation material was used to cover the seam around the lid of the test tank after the lid was closed. This practice has proven to be very effective in minimizing evaporation. To maintain the test temperature at $125{ }^{\circ} \mathrm{C}$, distilled water must be replenished periodically because the electrical power to the heaters would be cut off had the liquid dropped below the preset level at $35.56 \mathrm{~cm}$ (14 in.) above the tank bottom.

Non-destructive UT and magnetic particle test (MT) may be conducted at the end of the large plate test. The MT will reveal the fine details of the cracking pattern on the plate surface and the UT will detect the subsurface crack propagation.

\section{TEST RESULTS}

The U-bend test was planned for 21 days, but some specimens were actually left under the test conditions for an extended period of time. No cracking was found throughout the entire time of exposure. In addition, none of the large plates (the as-welded or the heat-treated) had exhibited any indication of stress corrosion cracking. 


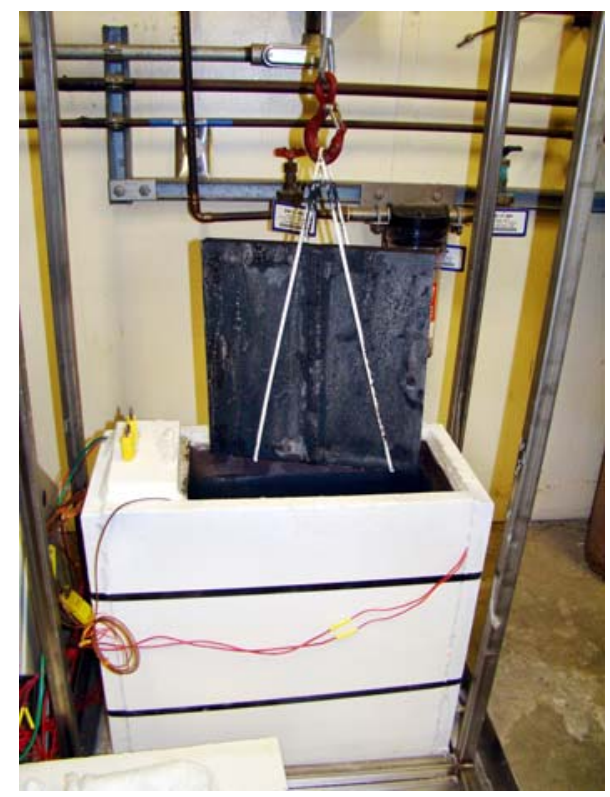

Fig. 12 Periodic inspection for cracking by lifting plate above the test solution.

\section{U-Bend Test Results}

The planned test time was 21 days, but some specimens were left in the heated beakers up to 95 days. During the first 21 days of testing, all specimens were inspected once a week for evidence of cracking. However, it should be noted that the salt concentrations might have been altered due to the loss of water for those specimens tested beyond 21 days even though Graham Condenser was installed for each test beaker. In all cases, no stress corrosion cracking could be found in the Ubend specimens. Typical photographs of specimens before and after exposure are shown in Figures 13 and 14 for as-welded and for heat-treated specimens, respectively. Both the outer side of the U-bend (tensile side) and the inner side (compressive side) are documented. Although the SCC on the compressive side is highly improbable, it is reported here for completeness.

\section{Large Plate Test Results}

The large plates had been submerged in the test solution at $125^{\circ} \mathrm{C}$ for 12 weeks at the end of the test. No stress corrosion cracking was found either in the as-welded plate or in the stress relieved/heat treated plate. The pre-exposure conditions of the plates can be seen in Figure 3 or Figure 10. Figures 15 and 16 are, respectively, the front and back sides of the as-welded plates after exposure for 12 weeks. The close-ups of the nine machined cracks in their post-test condition are shown in the insets. For the heat-treated plate, the post-test photographs are shown in Figures 17 (front side) and 18 (back side). Note that in Figures 15 to $18, \mathrm{~V} 1, \mathrm{~V} 2$, and V3 are through-the-plate

cracks and are across the width of the weld (vertical cracks); $\mathrm{V} 4, \mathrm{~V} 5$, and V6 are also vertical cracks (perpendicular to the weld) but they are partly through plate $(6.35 \mathrm{~mm}$ or $1 / 4$ in. deep thumbnail cracks) in the HAZ; and $\mathrm{P} 1, \mathrm{P} 2$, and $\mathrm{P} 3$ are partthrough plate $(6.35 \mathrm{~mm}$ or $1 / 4$ in. deep thumbnail cracks) cracks parallel to the weld and in the HAZ. On the back side of each plate, only three through-the-plate cracks are visible.

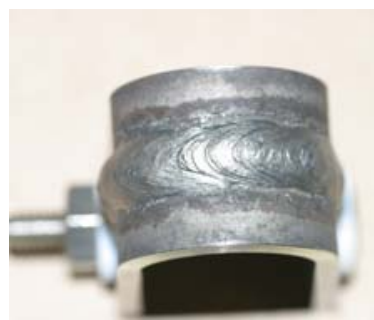

(a) Tensile side of U-bend before exposure

(c) Compressive side of U-bend before exposure

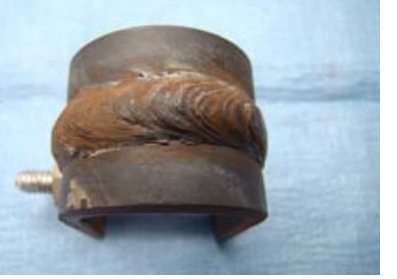

(b) Tensile side of U-bend after exposure

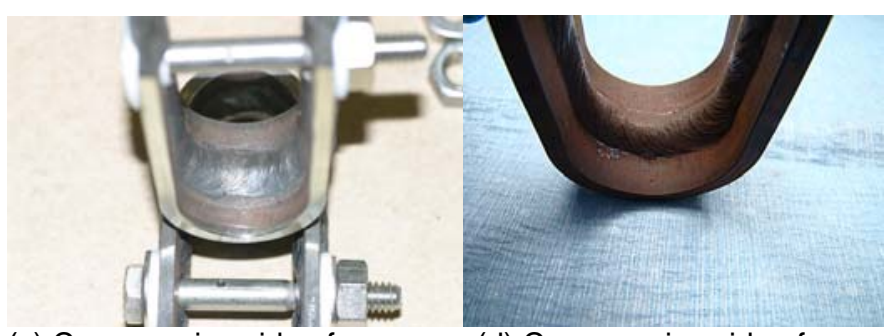

Fig. 13 As-welded Specimen (No. 247) exposed to caustic solution for 95 days.

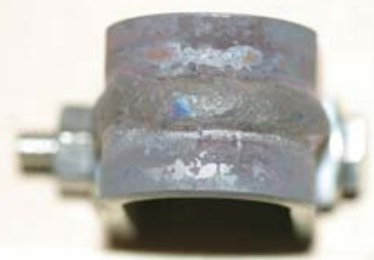

(a) Tensile side of U-bend before exposure

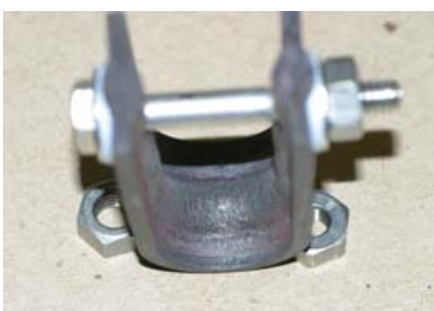

(c) Compressive side of U-bend before exposure

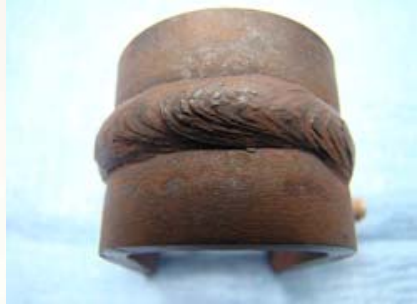

(b) Tensile side of U-bend after exposure

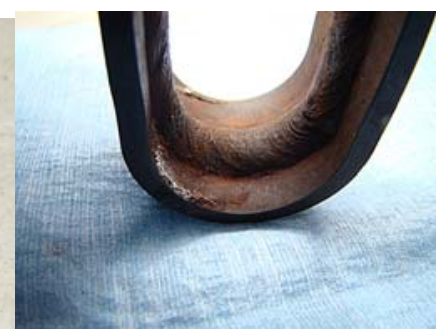

(d) Compressive side of U-bend after exposure
Fig. 14 Heat-treated Specimen (No. 243) exposed to caustic solution for 95 days. 
The post-test large plates were visually inspected carefully for evidence of stress corrosion cracking on the specimen surfaces. The close-up photograph of each individual crack can be seen in the inset in Figures 15 to 18 . In addition, nondestructive testing was conducted prior to and at the completion of exposure. Volumetric (ultrasonic shear wave) inspections were performed in search of cracking either parallel or perpendicular to the weld. Ultrasonic testing was performed utilizing 45-degree, $4 \mathrm{MHz}$ shear waves in a pitch-catch technique. Sensitivity was established from a $1.27 \mathrm{~mm}$ deep notch with data recorded over $115 \mathrm{~dB}$ range. This technique has proven to be effective in imaging the crack tips and facets from SCC. Ultrasonic shear wave inspections confirmed visual findings that there was no stress corrosion cracking or increase in length of the machined notch. Because no cracking was found, the magnetic particle testing (MT) was not performed.

P-scan images in Figures 19 and 20 indicate that no caustic stress corrosion cracking had grown in the direction parallel to the weld, for both the as-welded and the heat-treated plates. Several machined cracks were marked on the figures (hatched rectangles) to identify the actual position of the ultrasonic signals on the plate. These figures also indicate that there were no crack length changes for the parallel machined cracks P1, $\mathrm{P} 2$, and P3. Ultrasonic scans were also performed parallel to the weld to detect any cracking perpendicular to the weld (see Fig. 21 for the as-welded plate). As concluded earlier by Figures 19 and 20, Figure 21 also shows no evidence for stress corrosion cracking. Since no cracking could be found by the ultrasonic scans in all directions, it can be concluded that stress corrosion cracking did not occur inside the plates.

It should be noted that the UT-inspection applied directly over the uneven surface of the weld beads is impractical and therefore was not performed. Should stress corrosion cracking occur in machined cracks V1, V2, and V3 (through-the-plate cracks across the weld), the indication of crack extension would have been detected by the scans in the heat-affected zone immediately next to the weld (such as in Figures 19 to 21).

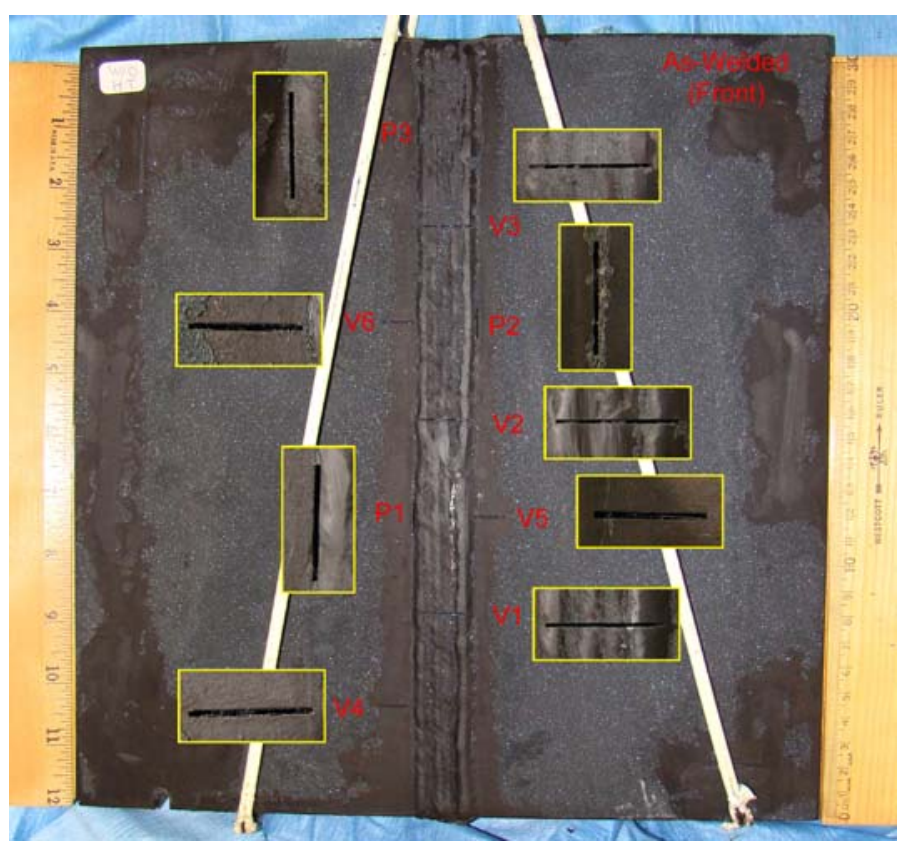

Fig. 15 As-welded plate after exposure to test solution for 12 weeks (Front side, insets show close-up machined cracks).

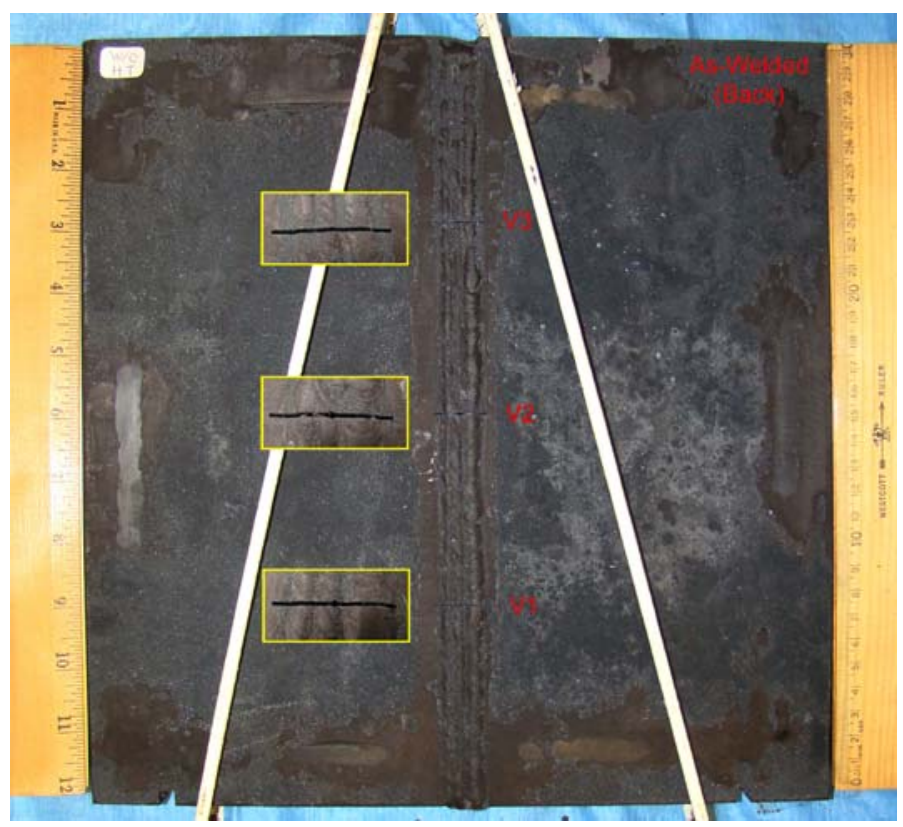

Fig. 16 As-welded plate after exposure to test solution for 12 weeks (Back side, insets show close-up machined cracks). 


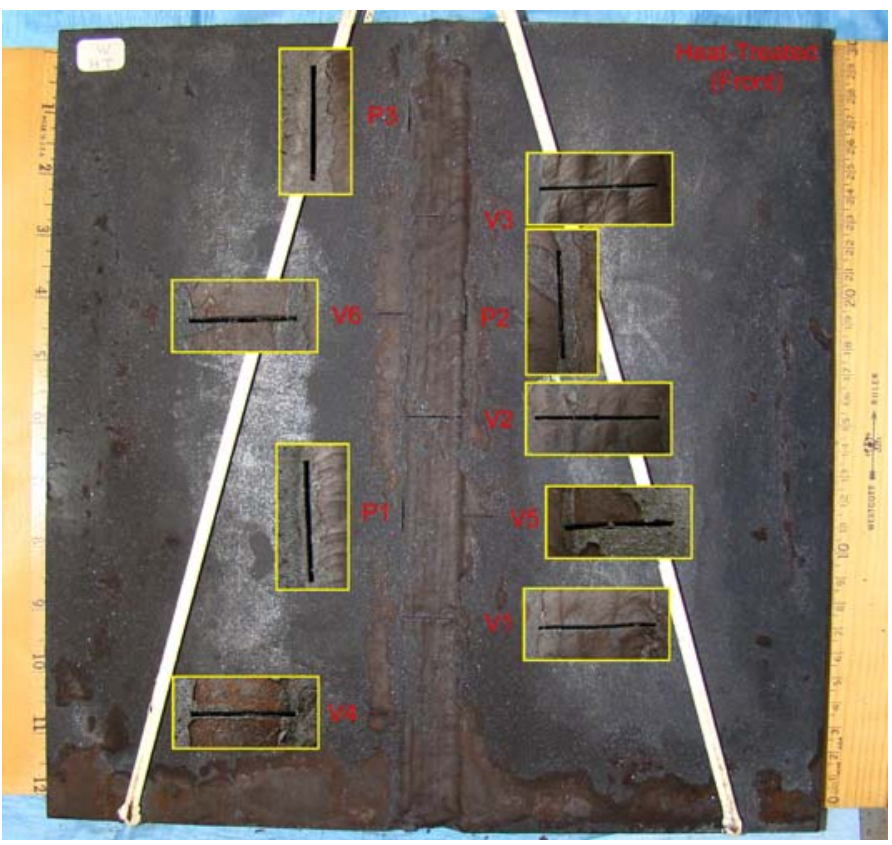

Fig. 17 Heat-treated plate after exposure to test solution for 12 weeks (Front side, insets show close-up machined cracks).

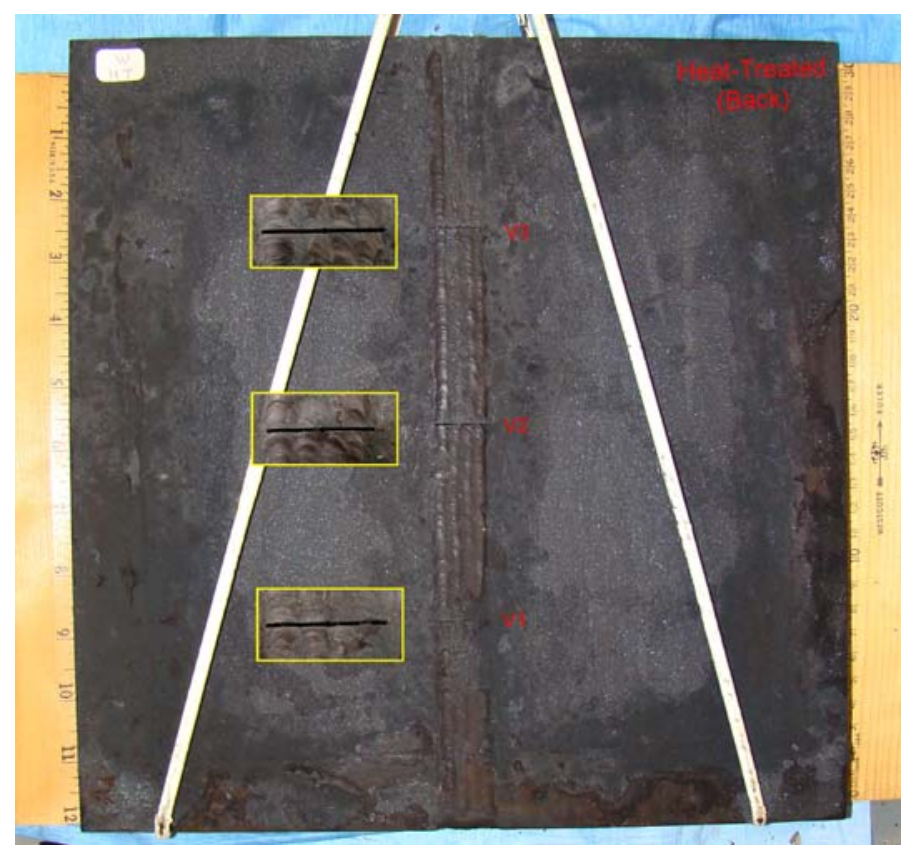

Fig. 18 Heat-treated plate after exposure to test solution for 12 weeks (Back side, insets show close-up machined cracks).

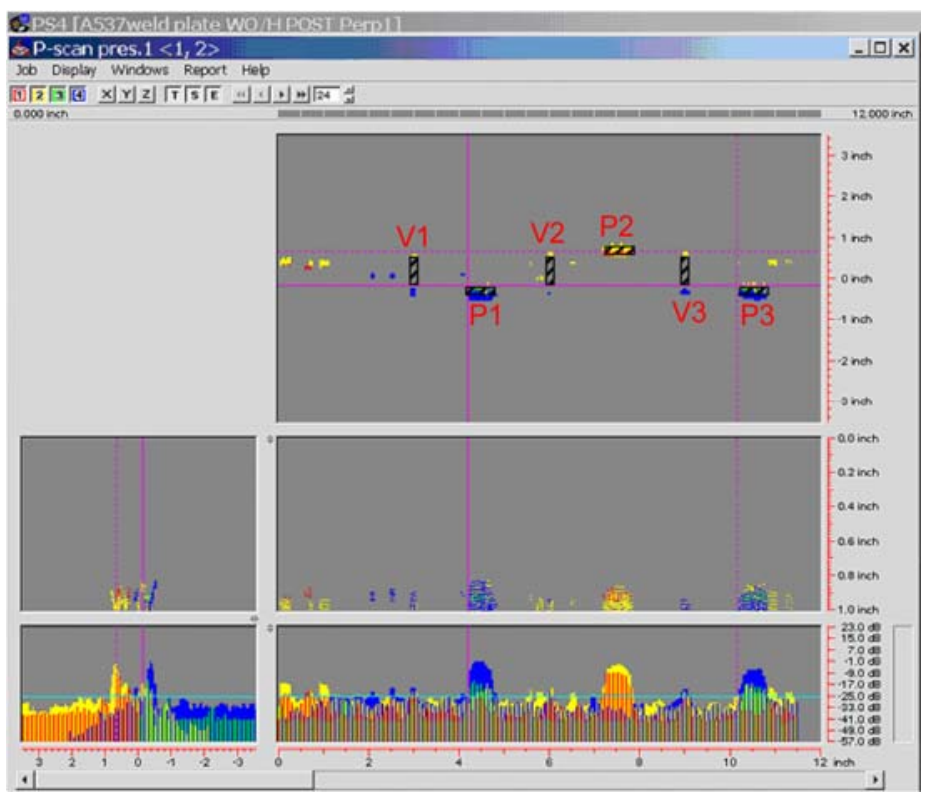

Fig. 19 P-scan for stress corrosion cracking parallel to the weld for the as-welded plate.

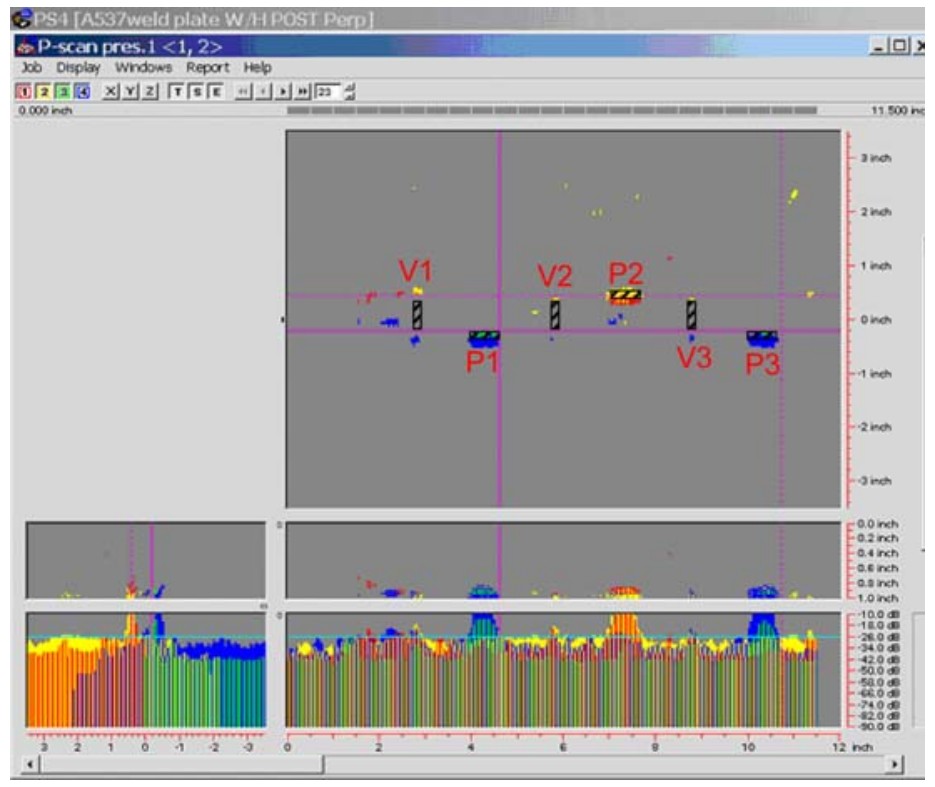

Fig. 20 P-scan for stress corrosion cracking parallel to the weld for the heat-treated and stress relieved plate. 


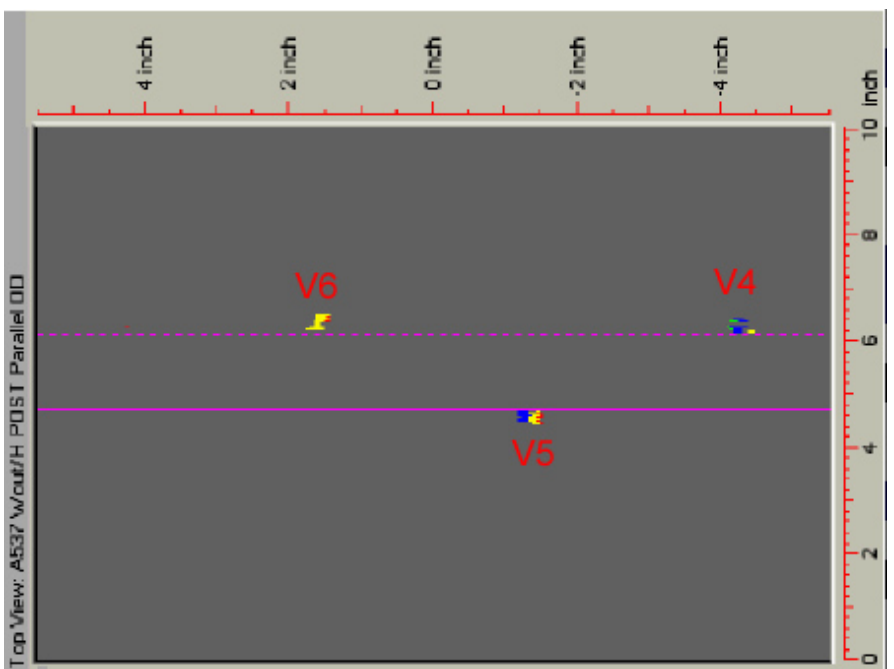

\section{Fig. 21 P-scan for stress corrosion cracking perpendicular to the weld for the as-welded plate.}

\section{CONCLUSIONS}

Based on the test results of the U-bend specimens and the large plates, it is concluded that stress corrosion cracking of A537 carbon steel did not take place in the high temperature $\left(125^{\circ} \mathrm{C}\right)$ caustic solution, which was composed of $12 \mathrm{M}$ hydroxide, and $1 \mathrm{M}$ each of nitrate, nitride, and aluminate (in the case of large plate test, the aluminate concentration was 0.3 $\mathrm{M})$. The actual temperature of the solution during the tests might be slightly higher than the target temperature of $125^{\circ} \mathrm{C}$ but was below the boiling point. The lack of caustic stress corrosion cracking indicates that the inhibitors, such as $\left[\mathrm{OH}^{-}\right]$ and $\left[\mathrm{NO}_{2}^{-}\right]$, maintain their adequate levels even when the solution temperatures are much higher than that specified in the waste tank corrosion control program. It is also possible that the nitrite ions, which are strong oxidizing agents, under this chemistry condition allow the formation of protective films on A537 carbon steel, even on the freshly exposed areas such as the Clarke's solution-treated machined cracks where the oxide was removed immediately before immersion. These mechanistic details may be addressed and resolved by electrochemical testing.

Careful examination of the specimen conditions found that many distinct surface features originally on the mill sheet remained visible on the large plate specimens after testing, and the appearance of the weld beads was essentially unchanged for both U-bend and large plate specimens. The specimen thinning was immeasurable with a micrometer. Therefore, the general corrosion is negligible for these specimens in $12 \mathrm{M}$ caustic solution for extended period of time.

The laboratory testing has demonstrated that stress corrosion cracking did not occur in the small welded U-bend specimens, as well as in the large plates where the welding procedure was identical to that used to construct this type of SRS nuclear waste tanks in the 1960s. The absence of evidence of stress corrosion cracking and general corrosion in the laboratory specimens indicate that this type of waste tank is not susceptible to highly caustic solutions up to $12 \mathrm{M}$ hydroxide at $125^{\circ} \mathrm{C}$ when sufficient nitrite inhibitor is present.

\section{ACKNOWLEDGMENTS}

The work was funded by the United States Department of Energy through Savannah River Remediation, LLC to Savannah River Nuclear Solutions, LLC under Contract No. DE-AC09-08SR22470. Ms. Tina M. Stefek of SRNL is greatly appreciated for her contribution to the safety and controls in the large plate testing. Ms. Robbie S. Garritano's (SRNL) assistance in mixing the test solutions and miscellaneous laboratory tasks is greatly appreciated. Thanks also go to Drs. John I. Mickalonis and Bruce J. Wiersma of SRNL for their technical advice and encouragements throughout the course of the work.

\section{REFERENCES}

[1] P.-S. Lam, C. Chang, Y. J. Chao, R. L. Sindelar, T. M. Stefek, and J. B. Elder, III, "Stress Corrosion Cracking of Carbon Steel Weldments," PVP2005-71327, Proceedings of ASME Pressure Vessels and Piping Conference, Denver, Colorado, 2005.

[2] ASTM G 1- 03, "Standard Practice for Preparing, Cleaning, and Evaluating Corrosion Test Specimens," ASTM International, West Conshohocken, Pennsylvania.

[3] ASTM G 123- 00 (Reapproved 2005), "Standard Test Method for Evaluating Stress Corrosion Cracking of Stainless Alloys with Different Nickel Content in Boiling Acidified Sodium Chloride Solution," ASTM International, West Conshohocken, Pennsylvania.

[4] ASTM G 30 - 97 (Reapproved 2003), "Standard Practice for Making and Using U-Bend StressCorrosion Test Specimens," ASTM International, West Conshohocken, Pennsylvania. 